\title{
POTENSI DAN PEMANFAATAN TANAMAN AREN (Arenga pinnata) DENGAN POLA AGROFORESTRI DI DESA PALAKKA, KECAMATAN BARRU, KABUPATEN BARRU
}

\author{
Potency and Use of Aren (Arenga pinnata) with Agroforestry Pattern in Palakka Village, Barru District, Barru Regency \\ Syarifah Majnah Ruslan ${ }^{1}$, Baharuddin ${ }^{2}$, Ira Taskirawati ${ }^{2}$ \\ ${ }^{1}$ Mahasiswa Fakultas Kehutanan Universitas Hasanuddin, Makassar \\ Lab. Pemanfaatan dan Pengolahan Hasil Hutan \\ 2 Staf Pengajar Fakultas Kehutanan Universitas Hasanuddin, Makassar, ${ }^{\bowtie}$ corresponding author: tasqira@unhas.ac.id
}

\begin{abstract}
Non-Timber Forest Products (HHBK) are part of the forest ecosystem that has a role to nature as well as to humans. One of the HHBKs that has high economic value and is one of the rural livelihoods of the community is Aren. This study aims to determine the potential and utilization of palm trees (aren) in Palakka Village Barru District Barru. The methods used are survey method and interview. Data analysis includes the potentials of sugar palms and description of the result of interview about the utilization of palm trees in Palakka village, Barru regency. The results showed that Palakka village has 15 palm trees that can already be in production, and 45 palm trees that have not been produced. Respondents utilize palm crop products as brown sugar and palm wine, other uses of palm trees that their fiber (ijuk) can be utilized to make palm-fiber broom; and the leaves are used as a funnel, roof of the house and palm-stick brooms.
\end{abstract}

Key words : Potency, Utilization, Aren, Agroforesri

\section{A. PENDAHULUAN}

Hasil Hutan Bukan Kayu (HHBK) merupakan bagian dari ekosistem hutan yang memiliki peran terhadap alam maupun terhadap manusia. HHBK telah dimanfaatkan oleh masyarakat sekitar hutan baik secara langsung maupun tidak langsung. Selain karena beberapa jenis HHBK mudah diperoleh dan tidak membutuhkan teknologi yang rumit untuk mendapatkannya juga karena HHBK dapat diperoleh secara gratis dan mempunyai nilai ekonomi yang penting. Hal ini menjelaskan bahwa keberadaan HHBK diyakini paling bersinggungan dengan kepentingan masyarakat sekitar hutan dalam memenuhi kebutuhan pangan, papan maupun ritual dan lainya. HHBK yang sudah dimanfaatkan dan dikomersilkan di antaranya adalah cendana, gaharu, sagu, rotan, aren,sukun, bambu, sutera alam, jernang, kemenyan, kayu putih, aneka tanaman obat, minyak atsiri dan madu. Salah satu HHBK yang memiliki nilai ekonomi tinggi dan merupakan salah satu sumber pencaharian masyarakat pedesaan adalah Arenga pinnata atau yang dikenal dengan enau atau aren (Suhesti \& Hadinoto, 2015).

Aren adalah salah satu jenis tanaman palma yang hampir tersebar di seluruh wilayah Indonesia. Seluruh bagian dari tanaman ini dapat dimanfaatkan mulai nira yang dapat diolah menjadi gula, dan nata de pinna; batangnya dapat diolah menjadi tepung aren; buah yang belum matang diolah menjadi kolang-kaling; daun diolah menjadi atap dan lidinya dapat dibuat menjadi sapu, serta

Diterima: 2 Februari 2018; Disetujui: 16 Maret 2018 ijuknya dapat diolah menjadi kerajinan. Di Indonesia luas tanaman aren belum diketahui secara pasti, Sembayang (2016) melakukan penelitian di 20 kabuapaten yang berada di Sumatera Utara dan dari hasil penelitian tersebut didapatkan data luas tanaman aren sekitar 5.29 hektar. Menurut Rumokoi (2004) dalam Syakir dan Karmawati (2009) dari pengolahan data yang dikeluarkan oleh Direktorat Jenderal Perkebunan (Ditjenbun) tahun 2003 dijelaskan bahwa total areal yang telah di tanami aren di seluruh Indonesia mencapai 60.482 ha, khusus Provinsi Sulawesi Selatan seluas 7.29 ha. Data terbaru mengenai luas tanaman aren di Sulawesi Selatan masih belum diketahui, begitupun data luas lahan tanaman aren yang di tanam pada areal agroforestri juga masih belum diketahui.

Agroforestri adalah suatu sistem penggunaan lahan yang bertujuan untuk mempertahankan atau meningkatkan hasil total secara lestari, dengan cara mengkombinasikan tanaman pangan/pakan ternak dengan tanaman pohon pada sebidang lahan yang sama, baik secara bersamaan atau secara bergantian, dengan menggunakan praktek-praktek pengolahan yang sesuai dengan kondisi ekologi, ekonomi, sosial dan budaya setempat (Hairiah dkk, 2003). Contoh kasus di Kabupaten Halmahera, pada lahan agroforestri ditanam banyak jenis tanaman, diantaranya adalah aren (Arenga pinnata Merr) sebagai tanaman utama sehingga daerah ini dikenal sebagai salah satu sentra agroforestri berbasis aren. Tamrin dkk (2015) melakukan penelitian, menunjukkan bahwa pengelolaan agroforestri berbasis aren dapat memberikan konstribusi terhadap 
peningkatan pendapatan rumah tangga di Desa Palakka, Kecamatan Barru, Kabupaten Barru.

Penelitian ini bertujuan mengetahui potensi dan pemanfaatan tanaman aren di Desa Palakka Kecamatan Barru Kabupaten Barru. Adapun kegunaan dari penelitian ini diharapkan menjadi salah satu informasi mengenai potensi aren khususnya yang dibudidayakan di lahan agroforestri yang ada di Sulawesi Selatan.

\section{B. BAHAN DAN METODE}

\section{Alat dan Bahan}

Pada penelitian ini menggunakan alat dan bahan yang terdiri atas tally sheet, pita ukur, tali rapiah, alat tulis, meteran, kamera, recorder dan kuesioner.

\section{Prosedur Penelitian}

Penelitian ini terbagi menjadi dua kegiatan. Kegiatan pertama adalah mengetahui potensi tanaman aren pada areal agroforestri di Desa Palakka dan kegiatan kedua adalah mengetahui pemanfaatan tanaman aren oleh masyarakat di Desa Palakka. Data yang dikumpulkan meliputi data primer dan data sekunder. Data primer yang dikumpulkan berupa luasan agroforestri, jumlah tanaman aren, dan pemanfaatan tanaman aren. Adapun data sekunder yang akan dikumpulkan berupa studi pustaka yang bersumber dari buku, jurnal, dan data-data dari instansi-instansi terkait.

\section{Penentuan sampel responden}

Responden pada penelitian ini adalah responden di Desa Palakka yang mempunyai lahan agroforestri sebanyak 13 responden.

\section{Teknik pengambilan data}

\section{Prosedur pengambilan data potensi tanaman aren di Desa Palakka}

Prosedur penelitian yang dilakukan yaitu menentukan lokasi agroforesteri yang akan diamati dengan menggunakan metode Survei. Menginventarisasi jumlah tanaman aren yang ada disetiap lahan agroforestri pada setiap tingkatan pertumbuhan. Semai dan pancang dikategorikan sebagai tingkat permudaan; tiang dan pohon sebagai klasifikasi tingkat lanjutan yang dapat menghasilkan. Mencatat data hasil pengamatan ke dalam tally sheet yang telah disiapkan. Menghitung potensi tanaman aren.

\section{Prosedur pengambilan data pemanfaatan tanaman aren di Desa Palakka}

Pengambilan data pemanfaatan tanaman aren akan dilakukan dengan cara Direct Observation yaitu pengumpulan data yang dilakukan untuk mendapatkan informasi secara langsung di lapangan mengenai pemanfaatan tanaman aren oleh masyarakat. Questioner yaitu sejumlah pertanyaan tertulis yang digunakan untuk memperoleh informasi dari responden secara terarah. Interview dilakukan dengan cara tanya jawab sambil bertatap muka langsung dengan masyarakat yang dijadikan sampel penelitian guna mendapatkan informasi tentang pemanfaatan tanaman Aren yang ditanam. Selama interview berlangsung, dilakukan recording dan pencatatan hasil wawancara.

\section{Analisis data}

Data yang telah dikumpulkan kemudian dianalisis dengan tahapan sebagai berikut: Analisis potensi tanaman aren. Diskripsl hasil wawancara mengenai pemanfaatan tanaman aren di Desa Palakka Kabupaten Barru.

\section{HASIL DAN PEMBAHASAN}

\section{Letak dan Luas Wilayah Penelitian}

Desa Palakka merupakan salah satu desa dari 10 desa yang berada di Kecamatan Barru Kabupaten Barru dengan luas wilayah $36,33 \mathrm{~km}^{2}$ dan sebagian besar wilayahnya terletak di daerah dataran tinggi. Jarak Desa Palakka dari ibu kota Kabupaten Barru adalah 8 km, sedangkan dari pusat lbukota Provinsi Sulawesi Selatan adalah 107,8 km. Desa Palakka dapat dicapai dengan menggunakan kendaraan roda dua maupun kendaraan roda empat dengan waktu tempuh \pm 3 jam dari kota Makassar. Batas wilayah administrasi desa palakka Sebelah utara berbatasan dengan Desa Galung, Sebelah selatan berbatasan dengan Kec. Tanete Riaja, Sebelah barat berbatasan dengan Kelurahan Sepe'e, Sebelah timur berbatasan dengan Desa Anabanua.

\section{Identitas Responden}

\section{Tingkat Pendidikan responden Aren di Desa palakka}

Hasil data menunjukkan tingkat pendidikan masyarakat di Desa Palakka masih sangat rendah, hal ini dapat dilihat pada Tabel 1.

Tabel 1. Karakteristik Responden Aren Berdasarkan Tingkat Pendidikan

\begin{tabular}{llcc}
\hline No. & Tingkat Pendidikan & \multicolumn{2}{c}{ Desa Palakka } \\
\cline { 3 - 4 } & $\begin{array}{c}\text { Jumlah } \\
\text { Responden } \\
\text { (Jiwa) }\end{array}$ & $\begin{array}{c}\text { Persen } \\
(\%)\end{array}$ \\
\hline 1 & Tidak sekolah & 4 & 30,7 \\
2 & SD & 5 & 38,4 \\
3 & SMP & - & - \\
4 & SMA & 3 & 23,0 \\
5 & Sarjana & 1 & 7,6 \\
\hline & Jumlah & 13 & 100 \\
\hline
\end{tabular}




\section{Tingkat Umur Responden Aren di Desa Palakka}

Tingkat umur berpengaruh terhadap kemampuan fisik responden dalam mengelolah usaha tani atau usaha lainnya yang dikerjakannya. Menurut data Badan Pusat Statistika (2002) menyatakan bahwa teori kependudukan pada usia produktif seseorang pada kisaran umur 15 tahun sampai 56 tahun pada negara-negara berkembang, dan usia sangat produktif 15 sampai 55 tahun. Kemampuan kerja seseorang dipengaruhi oleh umurnya, karena kemampuan kerja produktif terus menerus dengan bertambahnya usia seseorang. Umumnya responden yang berumur muda dan sehat jasmaninya memiliki kemampuan fisik yang lebih kuat dan inovatif dalam usaha pemanfaatannya. Responden yang masih muda juga akan lebih dianjurkan karena biasanya lebih berani menanggung apabila tejadi kendala walaupun masih kurang mamiliki pengalaman yang cukup. Selain semakin tua umur responden maka kemampuan fisiknya dalam bekerja relative berkurang namun responden usia tua lebih banyak memiliki pengalaman yang mahir dalam usaha pemanfaatannya. Oleh Karena itu, usia seseorang sangat mempengaruhi kematangan seseorang dalam bepikir dan bertindak.

Tabel 2. Karakteristik Responden Aren Berdasarkan Kelompok Umur

\begin{tabular}{llcc}
\hline & & \multicolumn{2}{c}{ Desa Palakka } \\
\cline { 3 - 4 } No. & $\quad$ Kelompok Umur & $\begin{array}{c}\text { Jumlah } \\
\text { Responden } \\
\text { (Jiwa) }\end{array}$ & $\begin{array}{c}\text { Persen } \\
(\%)\end{array}$ \\
\hline 1 & $\begin{array}{l}\text { Belum produktif (<15 } \\
\text { tahun) }\end{array}$ & 0 & 0 \\
2 & $\begin{array}{l}\text { Produktif } \\
\text { Tidak produktif } \\
\text { tahun) }\end{array}$ & 7 & 54 \\
& Jumlah & 6 & 46 \\
\hline
\end{tabular}

Tabel 2 menunjukkan bahwa persentase responden aren di Desa Palakka dengan kelompok umur produktif adalah sebesar $54 \%$, sedangkan responden aren yang sudah tidak produktif yaitu sebesar $46 \%$. Hal ini menunjukka bahwa usia responden aren yang ada di Desa Palakka masih mampu untuk bekerja dan mengelolah tanaman arena tau usaha lainnya.

\section{Agroforestri di Desa Palakka}

Lahan agroforestri di Desa Palakka seluas $0.66 \mathrm{Ha}$. Lahan ini dimiliki oleh 13 kepala keluarga yang merupakan responden pada penelitian ini. Adapun luas masing-masing lahan responden dapat dilihat pada Tabel 3.

Luas lahan agroforestri untuk setiap responden bekisar antara $0.02 \mathrm{Ha}$ (Dusun Cenne) sampai $0.08 \mathrm{Ha}$ (Dusun Camming). Tanaman yang tumbuh pada area agroforestri ini adalah tanaman kehutanan seperti bambu, rotan, dan jati serta tanaman pertanian seperti pisang, nangka, dan mangga. Aren merupakan salah satu jenis tanaman yang juga tumbuh di lahan ini. Keberadaan tanaman aren di area agroforestri ini, ada yang tumbuh alami namun ada juga yang memang sengaja ditanam oleh masyarakat.

Tabel 3. Luas lahan agroforestri di Desa Palakka Kabupaten Barru

\begin{tabular}{|c|c|c|c|c|}
\hline No. & Responden & $\begin{array}{l}\text { Luas } \\
\text { Lahan } \\
\text { (ha) }\end{array}$ & Dusun & $\begin{array}{c}\text { Luas } \\
\text { Lahan } \\
\text { (ha) }\end{array}$ \\
\hline 1 & Masse & 0,03 & Cenne & 0.13 \\
\hline 2 & Taswin & 0,02 & & \\
\hline 3 & Satir Ungo & 0,08 & & \\
\hline 4 & Sade & 0,08 & Camming & 0,42 \\
\hline 5 & Sudirman & 0,05 & & \\
\hline 6 & Sudirman & 0,05 & & \\
\hline 7 & Latif & 0,05 & & \\
\hline 8 & Ujedi & 0,05 & & \\
\hline 9 & Syamsu Alam & 0,07 & & \\
\hline 10 & Sudirman & 0,08 & & \\
\hline 11 & Adhang & 0,05 & Karengge & 0,12 \\
\hline 12 & Nawir & 0,05 & & \\
\hline \multirow[t]{2}{*}{13} & Dammare & 0,02 & & \\
\hline & Jumlah & 0,66 & & \\
\hline
\end{tabular}

\section{Potensi Tegakan Aren}

Tabel 4 menunjukkan pohon aren di Desa Palakka yang sudah berproduksi sebanyak 15 pohon dan pohon aren yang belum berproduksi sebanyak 43 pohon.

Table 4. Kategori Tanama Aren Berdasarkan Kemampuan Produksi Tanaman Aren di Desa Palakka Kabupaten Barru

\begin{tabular}{llcc}
\hline No. & Dusun & Berproduksi & $\begin{array}{c}\text { Belum } \\
\text { berproduksi }\end{array}$ \\
\hline 1 & Cenne & 4 & 13 \\
2 & Camming & 6 & 27 \\
3 & Karengge & 5 & 3 \\
\hline & Jumlah & 15 & 43 \\
\hline
\end{tabular}

Pada Dusun Cenne pohon aren yang sudah berproduksi sebanyak 4 pohon, yang belum berproduksi sebanyak 13 pohon aren pada Dusun Camming yang belum berproduksi sebanyak 6 pohon aren, yang belum berproduksi 27 pohon. Sementara untuk Dusun Karengge yang sudah berproduksi sebanyak 5 pohon, sedangkan pohon aren yang belum berproduksi sebanyak 3, Jika dilihat dari tiap dusun maupun Desa Pallakka secara keseluruhan, potensi tanaman aren di Desa Pallakka sangat rendah, Apabila masyarakat di ketiga dusun tersebut membiarkan hal ini terjadi, maka pada masa akan datang, tanaman aren di Desa ini akan hilang. Penanganan yang harus dilakukan adalah melakukan perbanyakan permudaan aren dengan cara penanaman. Jika hal ini tidak dilakukan, akan terjadi 
kehilangan bahan baku untuk pembuatan nira dan lainnya.

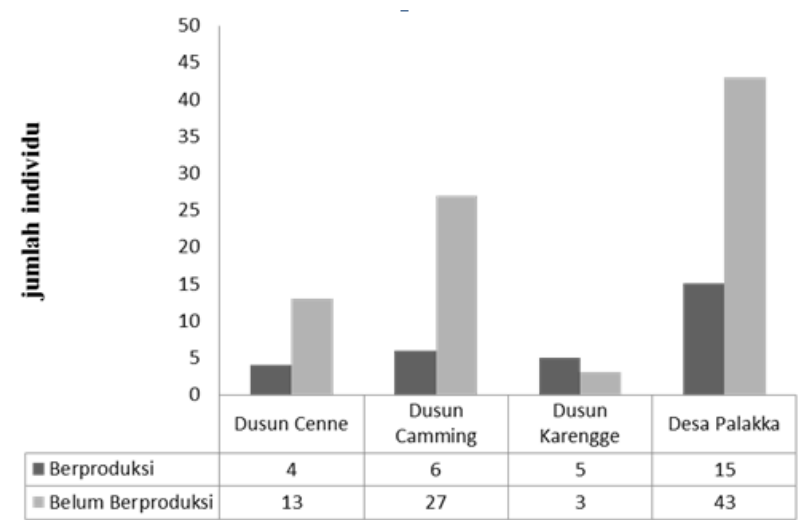

Gambar 1. Potensi Tanaman Aren pada Tiap Dusun di Desa Palakka kabupaten Barru

\section{Pemanfaatan Tanaman Aren di Desa Palakka Kabupaten Barru}

Tanaman aren dapat berproduksi pada umur tujuh tahun apabila responden melakukan pemeliharaan. Tanaman aren akan lama berproduksi apabila tanaman aren tidak dirawat. Tanda bahwa tanaman aren ini sudah mampu berproduksi adalahi adanya mayang bunga pada pelepah atau bekas pelepah daun. Aren dimanfaatkan dalam berbagi bentuk pemanfaatan dan setiap bagian aren dapat dimanfaatkan dengan tujuan tertentu. Di Desa Palakka, hanya memanfaatkan enam macam pemanfaatan aren. Hal ini disebabkan karena kurangnya pengetahuan responden aren terhadap pemanfaatan aren dan adapun responden aren lainnya yang telah mengetahui pemanfaatan tetapi hanya membiarkan pemanfaatan itu tanpa berfikir untuk mengolahnya.

Tabel 5. Produk dari Aren yang Dikomsumsi dan Dijual oleh Masyarakat Desa Palakka Kabupaten Barru.

\begin{tabular}{llcccc}
\hline & \multirow{2}{*}{ Pemanfaatan } & \multicolumn{2}{c}{ Dikonsumsi } & \multicolumn{2}{c}{ Dijual } \\
\cline { 3 - 6 } & $\begin{array}{c}\text { Jumlah } \\
\text { responden }\end{array}$ & $\begin{array}{c}\text { Persen } \\
(\%)\end{array}$ & $\begin{array}{c}\text { Jumlah } \\
\text { Responden }\end{array}$ & $\begin{array}{c}\text { Persen } \\
(\%)\end{array}$ \\
\hline $\begin{array}{l}\text { Bunga } \\
\text { (nira) }\end{array}$ & Gula merah & 6 & 46 & 6 & 46 \\
& $\begin{array}{l}\text { Pembuatan } \\
\text { tuak }\end{array}$ & 4 & 30 & 3 & 23 \\
\hline Daun & Atap rumah & 1 & 8 & - & - \\
& Sapu ijuk & - & - & 2 & 15,3 \\
& Sapu lidi & 1 & 8 & 2 & 15,3 \\
& Corong & 1 & 8 & - & - \\
\hline & Jumlah & 13 & 100 & 13 & 100 \\
\hline
\end{tabular}

Table 5 menunjukkan bahwa gula merah, merupakan produk paling banyak dikomsumsi dan dijual oleh responden Desa Palakka, masing-masing $46 \%$.
Marianti (2013) melakukan penelitian di Kalimantan Timur tepatnya di Desa Kandolo, selain di olah menjadi gula aren responden Desa Kandolo juga membuat gula cetak dan kadang-kadang juga membuat gula semut yang di campur dengan jahe dan pasak bumi. Responden Desa Palakka juga mengelola nira dengan membuatnya menjadi tuak. Tuak yang diproduksi, 30\% dikomsumsi sendiri dan hanya $23 \%$ dijual. Produk lain yang dihasilkan adalah atap rumah, sapu ijuk, dan corong; masing-masing $8 \%$ digunakan untuk konsumsi sendiri. Sapu ijuk dan sapu lidi sebesar $15.3 \%$ di produksi untuk dijual.

\section{KESIMPULAN}

Desa palakka memiliki potensi tanaman aren sebanyak 58 pohon. Sebanyak 15 pohon sudah dapat berproduksi dan sisanya belum berproduksi. Pemanfaatan tanaman aren di Desa Palakka adalah menjadikan nira sebagai gula merah dan tuak, selain itu tanaman aren juga dimanfaatkan untuk dibuat atap rumah, sapu ijuk, sapu lidi dan corong.

\section{E. DAFTAR PUSTAKA}

Hairiah, K., M.A. Sardjono \& S. Sabarnurdin. 2003. Pengantar Agroforestri. Bahan ajaran agroforestri 1. World Agroforestry Centre (ICRAF) Southeast Asia. Bogor.

Mariati, R. 2013. Potensi Produksi dan Prospek PengembanganTanaman Aren ( Arenga Pinnata MERR) di Kalimantan Timur. Staf Pengajar Jurusan Agribisnis Fakultas Pertanian Universitas Mulawarman Samarinda, Indonesia.

Sembayang, L. 2016. Keragaman Eksisting Tanaman Aren (Arenga Pinnata Merr) di Sumatera Utara (Peluang dan Potensi Pengembagannya). Balai Pengkajian Teknologi Pertanian Sumatera Utara.

Suhesti, E \& Hadinoto. 2015. Hasil Hutan Bukan Kayu Madu Salang di Kabupaten Kampar (Studi Kasus : Kecamatan Kampar Kiri Tengah). Fakultas Kehutanan Universitas Lancang Riau. P:16-26

Syakir, M dan E. Karmawati. 2009. Tanaman Perkebunan Penghasil Bahan Bakar Nabati (BBN). Badan Penelitian dan Pengambangan Pertanian, Pusat Penelitian dan Pengambangan Perkebunan. Bogor. P: 3-10.

Tamrin, M. L. Sundawati \& N. Wijayanto. 2015. Strategi Pengelolaan Agroforestri Berbasis Aren di Pulau Bacan Kabupaten Halmahera Selatan. Sekolah Pascasarjana Institut Pertanian Bogor (IPB). Bogor. 